\title{
Validation of a Model of Sustainable Place Value Understanding in Turkey
}

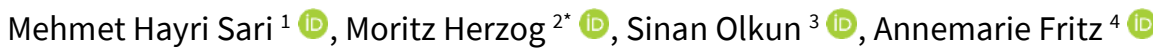

\author{
${ }^{1}$ Nevsehir Haci Bektas Veli University, Department of Basic Education, Nevsehir, TURKEY \\ ${ }^{2}$ University of Wuppertal, Institute of Educational Research, Wuppertal, GERMANY \\ ${ }^{3}$ Final International University, Department of Mathematics and Science Education, Kyrenia, NORTHERN CYPRUS \\ ${ }^{4}$ Academy Word + Number, International Institut for Intercultural Education, Köln, GERMANY \\ *Corresponding Author: mherzog@uni-wuppertal.de
}

Citation: Sari, M. H., Herzog, M., Olkun, S., \& Fritz, A. (2021). Validation of a Model of Sustainable Place Value Understanding in Turkey. International Electronic Journal of Mathematics Education, 16(3), em0659. https://doi.org/10.29333/iejme/11295

\section{ARTICLE INFO}

Received: 4 Jun. 2021

Accepted: 14 Sep. 2021

\begin{abstract}
Research has shown that a profound place value understanding is crucial for success in learning mathematics. At the same time, a substantial number of students struggles with developing a sustainable place value understanding. In this regard, two aspects of the place value system appear especially relevant: First, the knowledge of the decimal structure of numbers, and second, the relation between the bundling units. To support teaching place value understanding, a developmental model of place value understanding focusing on both aspects has been constructed and validated in Germany. The model comprises five levels of place value understanding that build upon each other hierarchically. This study aims at validating the level hierarchy in Turkey to prepare the usage of the developmental model as learning trajectory for Turkish primary schools.

$\mathrm{N}=437$ Turkish students from Grades 2 through 4 completed a translated version of the item collection of the German validation study as well as a Turkish place value test that is not based on a developmental model. In a Rasch analysis, most items of the translated item collection showed item difficulties as predicted by the model. In a regression analysis, item difficulties were well predicted by their allocation within the level hierarchy, while other item characteristics did not inform about the item difficulties. Substantial correlations between the translated item collection and the Turkish test underpin the claim that the model is appropriate to assess Turkish students' place value understanding as well as structuring place value instruction in Turkish primary schools.
\end{abstract}

Keywords: learning trajectory, mathematical development, place value understanding, Rasch analysis, validation

\section{INTRODUCTION}

Understanding the place value system is one of the important competencies for the further development of arithmetic skills such as the development of multi-digit numbers and operations with them (Dietrich et al., 2016) as well as other basic numerical competencies (Lambert \& Moeller, 2019) such as mentally representing the magnitudes of numbers. Similarly, children who understand the decimal structure of numbers flexibly (Ladel \& Kortenkamp, 2016) are more likely to solve math problems and do basic operations successfully (Gebhardt et al., 2014). A profound understanding of the place value system also facilitates the expansion of the number systems into decimal fractions (Moloney \& Stacey, 1997). Thus, students' understanding of place value system seems to be a prerequisite for the learning of further mathematics (MacDonald, 2008; McGuire \& Kinzie, 2013; Nataraj \& Thomas, 2007) since the place value constitutes the infrastructure of many areas of the mathematics program in schools.

Empirical studies have shown that a lack of place value understanding is a typical characteristic of children with math learning difficulties (Fuson et al., 1997; Gervasoni \& Sullivan, 2007; Hart, 2009; Lambert \& Moeller, 2019). The specific difficulty of the place value system could be empirically found already in children at the end of Grade 1 (Clarke et al., 2006). Downton et al. (2020) recently revealed that the place value aspect of the associative property of multiplication (e.g., $30 \times 40=3 \times 4 \times 10 \times 10$ ) is significantly harder for children to understand than other aspects such as doubling and halving (e.g., $6 \times 25=3 \times 2 \times 25$ ).

At least two difficulties with place value understanding have been highlighted by research. First, reading and writing numbers - so-called transcoding - is a skill that develops gradually during primary school (Moura et al., 2013). Especially at the beginning of school, children have difficulties with applying transcoding rules properly, leading to incorrect number notation such as "60042" instead of "642" (Byrge et al., 2014; Zuber et al., 2009). These types of errors illustrate how transcoding processes require identifying and coordinating the decimal bundle units (hundreds, tens, etc.) within a number representation. As every digit in a numeral refers to a specific bundling unit, this so-called position property is involved with transcoding difficulties (Moura et al., 
2013; Ross, 1989). This is in line with findings that show how transcoding is affected by the structure of number words (Dowker \& Roberts, 2015; Imbo et al., 2014; Zuber et al., 2009). In particular the tens-unit inversion found in some Germanic languages affects transcoding processes, as the units part of a number word is spoken before the tens part (Dowker \& Roberts, 2015; Klein et al., 2013; Lonnemann \& Yan, 2015; Zuber et al., 2009). The second aspect is that the decimal bundling units can be transferred, as ten units form one ten and similarly for bigger bundling units. This property is facilitated by the base-ten property which is that all bundling units are powers of ten (Ross, 1989). The base-ten property allows representing numbers "non-canonically", for example "35" as two tens and fifteen units (Ross, 1989). Non-canonical number representations challenge students, which indicates that the base-ten property challenges students substantially (Laski et al., 2014; Ross, 1989). These findings highlight the importance of a profound place value understanding for children's mathematical development. But which kind of knowledge do children need to understand the decimal place value system?

Research differentiates between procedural and conceptual place value understanding (Hiebert \& Lefevre, 1986; RittleJohnson \& Schneider, 2015; Van de Walle et al., 2016). Procedural place value understanding refers to the knowledge of how numbers are composed of decimal bundling units such as hundreds, ten, and units. Based on procedural place value understanding, children can decompose numbers and interrelate different visualizations, for instance Arabic numerals or baseten blocks. Conceptual place value understanding, however, refers to the knowledge of what the decimal bundling units actually mean and how they are related. Children apply their conceptual understanding of the relations between the bundling units to transfer one ten into ten units and vice versa. Thus, procedural place value understanding can be roughly identified with an understanding of the positional property while conceptual place value understanding mostly refers to the base-ten property. Note that procedural and conceptual place value understanding are intertwined: Procedural place value understanding requires conceptual understanding on the one hand and on the other hand conceptual place value understanding changes the procedures children apply in place value tasks (Rittle-Johnson \& Schneider, 2015).

For this reason, the effective provision of conceptual and procedural understanding in the concept of place value and its handling together may play an important role in learning and understanding mathematics (Sarı \& Olkun, 2019). Failure in adequately understanding the place value concept will be limiting the future mathematics achievement of both normal developing children and of those having difficulties in learning mathematics and causes hardships in the education of many children (Byrge et al., 2014).

To help addressing children's difficulties with place value understanding, a developmental model of place value understanding was constructed and empirically validated in Germany recently (Herzog et al., 2019; Herzog \& Fritz, 2019). In total, the model covers five levels of place value understanding that describe students' typical learning trajectories while developing a profound understanding of the decimal place value system. The model is based on a constructivist notion of development. That means that it is not the understanding of the place value system that develops and emerges autonomously. Rather do the students actively develop a place value understanding through interaction (Gravemeijer, 2004). Children's interaction with the place value system might be initiated through both formal or informal instruction (Dehaene, 2011). During this process, most students follow similar developmental trajectories that are characterized by specific representations, strategies, and errors (Confrey, 2006). The developmental model by Herzog et al. (2019) describes these typical developmental trajectories. Based on the model, place value instruction can be aligned to children's developmental trajectories (Clements \& Sarama, 2004).

The model is based on a detailed review of the structure of the place value system and existing models for two-digit place value understanding (Cobb \& Wheatley, 1988; Fuson et al., 1997; Ross, 1989; Wright et al., 2007). Besides a theoretical foundation, the model is based on several piloting studies (Herzog et al., 2019). The model was constructed in a circular process of theoretical considerations and empirical pilot studies. After constructing a theory-based model, this model was operationalized and tested. The results of the pilot studies were discussed within the context of the model, which led to a critical revision of the model (Battista, 2011). This process was completed when the operationalization did not contradict the theoretical assumptions anymore.

The levels build up on each other, forming a hierarchical sequence. Students need the knowledge from previous levels to develop the understanding of subsequent levels. The levels do not replace each other, but rather are interrelated. Higher levels are elaborations of lower levels as described in the overlapping waves account (Clements \& Sarama, 2014; Siegler \& Alibali, 2005).

Pre-decadic Level: Initially, students understand numbers as unitary entities that are not decimally structured (Boulton-Lewis, 1998; Cobb \& Wheatley, 1989; Fuson et al., 1997; Ross, 1989). While students may be able to decompose numbers (e.g., 12 in 6 and 6 or 10 and 2), the decomposition into tens and units is not special to them. Children at this level do not yet know that the decimal bundling units structure multi-digit numbers.

Level I (Place Values): The first level of place value understanding is knowing the bundling units (units, tens, hundreds etc.) and mapping them to the digits in a multi-digit number (Boulton-Lewis, 1998; Cobb \& Wheatley, 1988; Fuson et al., 1997; Ross, 1989; Wright et al., 2007). In particular, this knowledge supports transcoding, as students rely on mapping digits and place values in transcoding. However, the bundling units are not interrelated at this level.

Level II (Tens-Units Relation with Visual Support): At this level students are able to interrelate tens and units when they are provided with structured visual representations of the bundling units (Cobb \& Wheatley, 1988; Wright et al., 2007). These representations can be manipulatives (e.g., base-ten blocks) or pictures. Children use the representations to verify the relation of tens and units. This knowledge is limited to tens and units at this level.

Level III (Tens-Units Relation without Visual Support): At this level, students have internalized the relation between tens and units allowing them to detach from visual support. They understand the relation between tens and units without using given representations. Similar to the representation-bound understanding of the relation between tens and units, students at this level can interrelate bigger bundling units (e.g., hundreds), when they are given visual support in the form of manipulatives or pictures. 
Level IV (General Decimal-Bundling-Unit Relations): At the fourth and last level, students have extended their abstract understanding of the relation between the bundling units onto bigger bundling units such as hundreds or thousands. They can interrelate decimal bundling units without visual support and without limitation of the number range.

The model was empirically validated in Germany in a cross-sectional and a longitudinal study (Herzog \& Fritz, 2019). While the cross-sectional study in Germany underpinned the assumptions of the internal hierarchy of the model, the longitudinal study provided evidence for significant growths in place value understanding according to the model. Thus, the model can be used to describe typical developmental routes German students follow while exploring the place value system (Clements \& Sarama, 2004).

Further evidence for the validity of the level sequence of the model is provided by international studies. For example, the level hierarchy of the model was confirmed in Grades 2 to 5 in South Africa. Given that, the learning conditions are very different in German and in the South African classrooms, this study aimed to investigate whether this level sequence model can be transferred to South Africa (Herzog et al., 2017). The development of place value concepts is bound to contextual aspects of learning. These include the formation of number words in the respective languages, teaching practices in the classrooms, and the curriculum. If the level hierarchy proposed by Herzog et al. (2019) really describes the typical learning trajectories of children when they develop a place value understanding, the level hierarchy is supposed to be rather independent from these contextual aspects of learning. The findings based on the responses of 198 Grade 2 through 5 learners showed that the English translation of the test items resulted in the same item level allocation as the original German test items, especially for the basic three levels (Herzog et al., 2017).

The present study aims at testing the level hierarchy in Turkish students. Given the structure of number words in German and English, in which the level hierarchy is bolstered by empirical data, Turkish number words differ in their transparency for numbers beyond twenty from both German and English. German number words are inverted, which means that the units are spoken before the tens (e.g., 42 = "zweiundvierzig"/"two-and-forty"). However, the tens words can easily be derived from the units and in most cases add the suffix "-zig" to the unit number word. English number words are not inverted, but similarly as in German, the tens number words are closely related with the unit number words (suffix "-ty"). Turkish number words however are not inverted and the decomposition in tens and unit parts is very clear (e.g., "kırk iki" = "forty two"). Unlike German and English number words, the words for tens are only for numbers beyond 60 linked to the unit number words (e.g., $4=$ dört, $40=$ kırk, but $6=$ altı, $60=$ altmış). In conclusion, Turkish number words appear to be less transparent than English, but more transparent than German number words for decades such as 20, 30, 40 etc. up to 100. However, it is more transparent than both English and German for numbers from 10 to 20. For example, 11 is on-bir=ten-one, 12 is on-iki=ten-two, etc. Therefore, the development of place value concepts in Turkish children might differ from their German and South African peers.

In an earlier study, Olkun et al. (2011) found that language differences did not significantly affect the students' use of canonic representations such as tens in solving problems that requires faster counting. The Herzog et al. (2019) model provides opportunity to investigate, how the structure of number words in Turkish affects students' use of non-canonical representations.

Students' understanding of canonical and non-canonical representations depends - among others - on the instruction in classrooms. In many parts of the world, children are introduced to the place value concept when they start primary school. For example, students in Germany learn two and three-digit numbers in the second grade. In grade 3, they learn numbers up to 1000 and in grade 4 up to 1 million. At the end of the third grade, they are required to know how the place value concept is applied to multi- digit numbers. In Turkey, children are introduced to the place value concept in the first grade at primary school; however, this introduction is limited to finding tens and ones in numbers up to 20 only. Combining tens and ones to form two-digit numbers and identifying tens and ones in numbers beyond 20 and up to 100 are introduced in the second grade. The place value concept is then strengthened by introducing three-digit numbers in the third grade, and four, five, six-digit numbers in the fourth grade (Ministry of Education, 2018). Both the German and Turkish curriculum focus on canonical representations. Moreover, the progression in regard of the number range is comparable. Thus, the Herzog et al. (2019) model might be used in Turkish primary school education, if the level sequence describes Turkish students' development of place value concepts.

\section{Research Questions}

These findings raise the question whether the model can serve as a theoretical, developmental-oriented framework for place value instruction in Turkey, too. Before applying the model in Turkish classrooms, the hierarchy of the level sequence needs to be tested. We will challenge the level hierarchy in Turkey guided by three research questions:

1. How do the item difficulties in the Turkish version align to the theoretical model?

We assume that items that operationalize the same level are of similar difficulty. The level hierarchy would be underpinned, if items of lower levels were easier than items on higher levels.

2. To what extent does the theoretical item assignment of the items to the levels uniquely predict item difficulties (compared to other item characteristics such as item format, number range, etc.)?

Based on the results of the German validation, we hypothesize that the item-level assignment predicts item difficulties substantially and better than other characteristics. Moreover, item characteristics such as response format or number range are expected to add only slightly to the explained variance of the item difficulties.

3. How does place value understanding in terms of the model correlate with performance in other place value tasks?

By comparing results from an existing Turkish test (without a developmental approach) for place value understanding with the results of the item collection based on the model by Herzog et al. (2019), we seek to show convergent validity of the model. If the model is appropriate to assess place value understanding in Turkish students, we expect a high correlation. 


\section{METHOD}

\section{Sample}

In total $\mathrm{N}=437$ Turkish students ( 213 female,) from Grades 2 to 4 participated in the study. 113 students visited Grade 2 ( 55 female), 170 were in Grade 3 ( 87 female) and 153 students were fourth-graders ( 71 female). The sample was conveniently drawn among $2^{\text {nd }}$ and $4^{\text {th }}$ graders from one primary school located in the central district of a mid-Anatolian city in Turkey. The participating school was a public school, located in a middle socioeconomic area.

Obviously, the socioeconomic status of students from a middle-class background differs between countries. Compared to the samples from Germany and South Africa that were involved in the model validation, the Turkish sample is somewhere in between as the average socioeconomic status of Germany is higher, while South Africa has a substantially lower socioeconomic status. The sample for the validation of the model that was conducted in Germany was drawn from schools of a middle socioeconomic background as well (Herzog \& Fritz, 2019). Keeping in mind the average difference in socioeconomic status between Germany and Turkey (e.g., OECD, 2019), the results of the Turkish sample can therefore be compared to the German sample. However, the South African sample was recruited from a less privileged background, which limits the comparability to the Turkish sample.

\section{Instruments}

To measure students' place value understanding in terms of the model proposed by Herzog et al. (2019), we employed an item collection of 36 items in total. The item collection had been used for the model validation in Germany in previous studies (Herzog \& Fritz, 2019). The original version was translated to Turkish and back to German by two independent translators beforehand. The two Turkish versions were discussed by German and Turkish speaking colleagues to guarantee that the final Turkish version of the item collection covered exactly the same concepts than the original version.

The 36 items are aligned to the model levels. 12 items correspond to Level I and 8 items operationalize the concepts of Level II to IV each. As all items were presented to all students in random order, we decided to include more items on the first Level to prevent students from being over-challenged. The items covered different formats and response modes to allow investigating the influence of response modes on item difficulties in relation to the a-priori level allocation. Typical formats used in the study were place-value charts, abstract decompositions (see Figure 4) and illustrations based on base-ten blocks (see Figure 1). The item collection included multiple choice items as well as open-ended items. All multiple-choice items had four response options to keep guessing probability at $25 \%$. The three distractors were chosen based on frequently made errors in the German validation study. The open-ended items were evaluated based on the mathematically correct answer only.

The Turkish place value test was developed for the second, third and fourth grades, based on the Primary School Mathematics Curriculum (2018). There are 27 questions for the second-grade students in primary school, 28 questions for the third-grade students and 22 questions for the fourth-grade students. Second grade place value test was developed by Paydar and Sarı (2019). The reliability of the test was Cronbach's $\alpha=.91$. The achievement test used for third graders was developed by Mutlu and Sarı (2019). Mutlu and Sarı (2019) found the KR-20 reliability coefficient as .89. The fourth-grade place value test was developed by Sarı and Olkun (2019). The reliability of the test was found to be .84. All of the tests include reading numbers, writing numbers, place value (e.g., in 13, 3 represents three ones and 1 represents one ten), face value (e.g., in 13, 3 represents three objects and 1 represents one object), grouping of numbers and regrouping of numbers. The open-ended items were evaluated based on the mathematical correct answer only.

\section{Results}

To address the first research question, to what extent item difficulties correspond to the model (RQ1), we employed a onedimensional Rasch analysis. A Rasch analysis is a probabilistic statistical model that measures item difficulties and person abilities on a common scale. Items with a higher difficulty score are less likely to be solved by any person; correspondingly, a person with a high ability score is more likely to solve any item. This method allows evaluating the difficulties of items. Additionally, differential item functioning (DIF) analyses can detect biases in certain items regarding subgroups in the sample. For example, a gender DIF can identify items that are systematically easier for boys or girls.

In a Rasch analysis comprising children from Grades 2 to 4, item difficulties of the items operationalizing the Turkish translation of the German test were estimated. Reliability statistics were good: EAP (item difficulties) was .906, WLE (person abilities) was .89. Important measures for a Rasch analysis are the infit values of the items. High-infit values mean that item difficulties are strongly predicted by the model, which indicates that the items are redundant. Low infit values mean that item difficulties are only slightly predicted by the model, which indicates that the items operationalize more than one construct (Linacre, 2002). Wilson (2005) recommends infit values between .7 and 1.3 for using Rasch analysis. Due to insufficient infit values, three items had to be removed from further analysis. The remaining 33 items showed acceptable MNSQ infit values (.79-1.27).

Table 1 comprises means, standard deviations, and ranges of item difficulties for items of each level. Most items cluster according to the theoretical allocations. Items difficulties increase for higher levels regarding means and ranges. Thus, the Rasch analysis supports the assumption of the model hierarchy. However, five items differed regarding their difficulty from the other items of the corresponding level. These so-called outliers are shown in Table 1, too. Outliers were only found at higher levels. There were no outliers at Level I and II. Two items regarding Level III deviated in difficulty. One item was easier, and one item was more difficult than predicted by the model. Three items operationalizing Level IV were easier than expected based on the theoretical allocation. No item deviated more than one level and the biggest deviation was 1.31 standard deviations. 
Table 1. Results of the Rasch analysis

\begin{tabular}{|c|c|c|c|c|}
\hline \multirow[t]{2}{*}{ Level } & \multicolumn{3}{|c|}{ Difficulty measure } & \multirow[t]{2}{*}{ Outliers (Difficulty) } \\
\hline & $M$ & $S D$ & Range (Min - Max) & \\
\hline Levell & -2.31 & .37 & $-3.14--1.89$ & - \\
\hline Level II & -1.33 & .19 & $-1.62--1.07$ & - \\
\hline Level III & .11 & 1.08 & $-1.40-.67$ & $9 c(-1.20), 3 c(1.53)$ \\
\hline Level IV & .86 & .68 & $1.06-1.89$ & $4 b(.46), 4 c(.12), 10 c(.03)$ \\
\hline
\end{tabular}

${ }^{*}$ Note: $\mathrm{M}=$ mean, $\mathrm{SD}=$ standard deviation

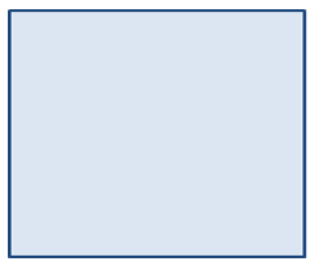

$\square \quad 1162$

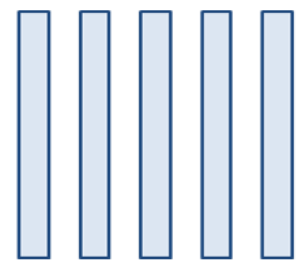

262

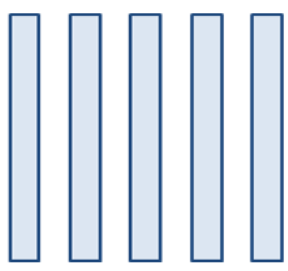

412

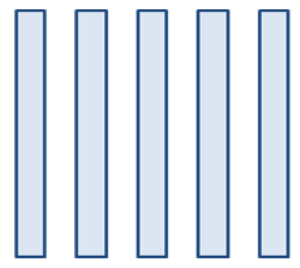

1312

Figure 1. Item $9 c$ from the translated test. (What number is this? Tick the correct box?)
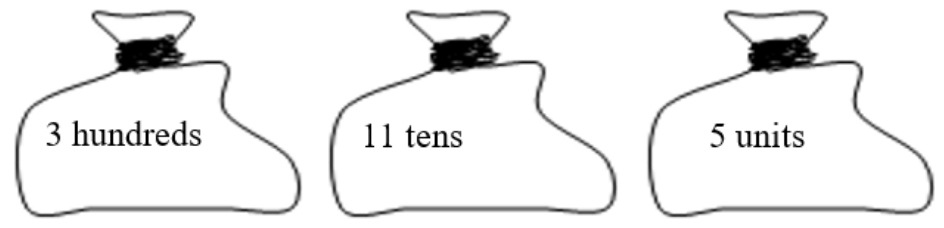

Figure 2. Item $10 \mathrm{c}$ from the translated test. (What number is in the bags?)

Așağıda verilen sayıdaki yüzler basamağını daire içine alınız.

\section{$3,4 \quad 2 \quad 1$}

Figure 3. Item 6 a from the translated test. (Circle the number representing hundredths in the number below)

Given the theoretical assumption of the levels as overlapping waves, outliers do not contradict the model hierarchy in general but need to be discussed. Item $3 c$ of the translated German test required regrouping of units into tens without visual support (Level III). 5 tens and 27 units were presented in a place value chart. This item was more difficult than other items at Level III.

The other deviating item at Level III (9c, see Figure 1) visualized one hundred, eleven tens and two units in the form of baseten blocks. Children had to tick the correct answer from four given choices. This item was substantially easier than other Level III items. One possible reason could be that children were more familiar with corresponding visualizations of hundreds than German children were. Level III describes two developmental branches (i.e. abstract bundling of units and tens as well as visualizationbased bundling of tens and hundreds) but indicates no hierarchy in these developmental branches. These results might reveal a hierarchy regarding detaching the tens-units relation from visualizations and extending the tens-units relation to bigger bundling units.

Items $4 \mathrm{~b}$ ("You have 5 hundreds and you take away 5 units. What number do you get?") and 4c ("You have 1 thousand and you take away 1 ten. What number do you get?") were quite similar and both easier than expected. These items required operating mentally with bundling units up to thousands without visualizations (Level IV). In both cases, children might have imagined the corresponding visualizations and performed the required operations in their minds with the imagined materials (Herzog \& Fritz, 2019). Based on this strategy, children were likely to solve these items with an understanding of Level III, driven by visualizations. In item 10c (Level IV), the children were presented three bags with 3 hundreds, 11 tens, and 5 units and asked, which number this is (see Figure 2). One possible explanation could be that children imagined the corresponding visualizations (i.e. one hundred plate, eleven ten sticks and one unit cube) to solve this items. These imagined visualizations might have supported children while bundling tens to hundreds. However, a very similar item of the same format with different numbers was as difficult as predicted (Rasch measure $=1.24$ ).

In an additional DIF analysis, items were investigated regarding systematically different difficulties for boys and girls. According to the Educational Testing Service (ETS) standards, differences in item difficulty of more than .638 logits have to be considered statistically significant and will be reported here (Zwick et al., 1999). In total, 3 items showed gender differences in difficulties slightly above this significance cut-off. Item 4c (described above) was easier for boys (DIF=.716 logits). Items 6a (DIF=.714 logits) and $6 \mathrm{~b}$ (DIF=.722 logits) were easier for girls. Items $6 \mathrm{a}$ (see Figure 3 ) and $6 \mathrm{~b}$ required to identify a given position in a multi-digit number, for example the hundreds place. Thus, items showed no systematical DIF regarding gender. 


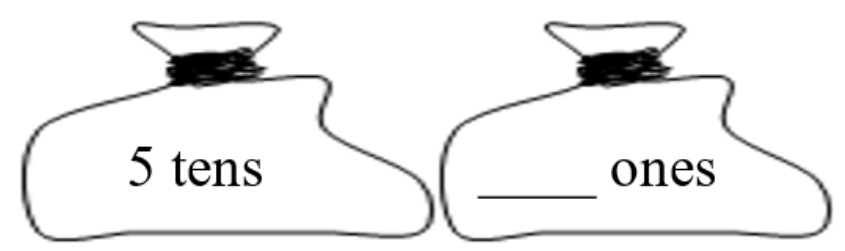

Torbada 63 tane şeker olması için kaç tane birlik lazım? Üzerine yazınız.

Figure 4. Item $5 \mathrm{~b}$ from the translated test. (How many ones are needed in order to have 63 candies in the bag? Write on it.)

Table 2. Dummy matrix used for the regression analysis

\begin{tabular}{|c|c|c|c|c|c|c|c|c|c|c|}
\hline \multirow[t]{2}{*}{ Item } & \multicolumn{4}{|c|}{ Level Alignement } & \multicolumn{4}{|c|}{ Item characteristics } & \multirow[t]{2}{*}{ Digits } & \multirow[t]{2}{*}{ Difficulty } \\
\hline & Level I & Level II & Level III & Level IV & MC & Base-ten & Fill in & Bags & & \\
\hline $9 b$ & 1 & 0 & 0 & 0 & 1 & 1 & 0 & 0 & 2 & $-2,564$ \\
\hline $3 c$ & 1 & 1 & 1 & 0 & 0 & 0 & 1 & 0 & 2 & 1,526 \\
\hline $5 b$ & 1 & 1 & 1 & 0 & 0 & 0 & 1 & 1 & 2 & ,484 \\
\hline $10 c$ & 1 & 1 & 1 & 1 & 0 & 0 & 0 & 1 & 3 &, 028 \\
\hline $1 b$ & 1 & 1 & 0 & 0 & 0 & 1 & 0 & 0 & 2 & $-1,290$ \\
\hline
\end{tabular}

Table 3. Results of the two regression models identifying predictors for item difficulties

\begin{tabular}{|c|c|c|c|c|c|c|}
\hline & \multicolumn{3}{|c|}{ Model 1 (adj. $\left.R^{2}=.805\right)$} & \multicolumn{3}{|c|}{ Model 2 (adj. $\left.R^{2}=.890\right)$} \\
\hline & b & $\mathbf{T}$ & $p$ & b & $\mathbf{T}$ & $p$ \\
\hline \multicolumn{7}{|l|}{ Level assignment } \\
\hline Level I (const) & -2.311 & -12.672 & $<.001$ & -2.223 & -4.690 & $<.001$ \\
\hline Level II & .982 & 3.269 & $<.01$ & 1.595 & 5.154 & $<.001$ \\
\hline Level III & 1.442 & 4.270 & $<.001$ & .767 & 2.453 & .022 \\
\hline Level IV & .746 & 2.209 & .035 & .582 & 2.031 & .053 \\
\hline \multicolumn{7}{|c|}{ Additional item characteristics } \\
\hline MC & - & - & - & .032 & .122 & .904 \\
\hline Base-ten & - & - & - & -.692 & -2.473 & .021 \\
\hline Fill in & - & - & - & .667 & 2.978 & $<.01$ \\
\hline Bags & - & - & - & .102 & .457 & .652 \\
\hline Digit & - & - & - & -.061 & -.413 & .683 \\
\hline
\end{tabular}

${ }^{\text {*Note. Significant parameters in bold }}$

A second research question (RQ2) was, to what extent item alignment to the levels of the developmental model predict item difficulties. Of special interest was, how other item characteristics such as response format, visualizations, or number range contributed to item difficulties in contrast to the a-priori alignment to the levels (for a similar approach see Schulz et al., 2020). For this purpose, two regression models were employed, based on a dummy matrix. In the dummy matrix, the items from the translated test were included as cases. The item difficulties obtained from the Rasch analysis were used as dependent variable. Three kinds of predictor variables were used. First, the level alignment was operationalized by four variables, one for each of the model levels. If an item was at this level or beyond, the variable was set at 1 , if the item was below the corresponding level, the variable was set at 0 . Second, four item characteristics were set at 1 if the characteristic applied to the item and 0 otherwise. The variable "MC" coded the response format (multiple choice or open ended). "Base-ten" referred to visualizations of base-ten blocks in the item (e.g., Figure 1). "Fill-in" represents if the item aimed at the whole number (e.g., Figure 2) or one of the bundling units (e.g., Figure 4). The last dichotomous variable "bags" operationalized if the bundling units were given in separate bags (e.g., Figure 2 and Figure 4). Third, the item number range ("digits") was coded as the number of digits of the biggest number involved in the item. Table 2 provides an insight into this matrix.

Based on the dummy matrix, two regression models were employed to identify the relevance of level alignment and item characteristics for item difficulties. The parameters of the two models are comprised in Table 3. In Model 1, only the variables operationalizing the level alignment to the Herzog et al. (2019) model were included $(F(3,29)=45.111, p<.001)$. This model accounted for $80.5 \%$ of the variance in the item difficulties, which is comparable to similar approaches (Schulz et al., 2020). Alignment to all levels predicted item difficulties significantly. Item characteristics and number range were added to the model $(F(8,24)=33.257, p<.001)$. Model 2 explained $89.0 \%$ of the variance in the item difficulties. The increase in explained variance of $8.5 \%$ was significant $(F(5,24)=5.437, p<.01)$. Levels I to III remained significant predictors of item difficulties, while Level IV was only close-to significance, when item characteristics were added. Of the additional item characteristics, only use of base-ten block pictures and embedded part-whole tasks predicted item difficulties significantly. Items with illustrations were associated with lower, items with part-whole formats were associated with higher item difficulties. Based on the results of Model 2, the unique influence of the item characteristics was investigated in a separate regression model. This model was not significant at all $(F(5$, $27)=1.965, p=.116$ ), explained $13.1 \%$ of the variance in item difficulties and no predictor was significant. In summary, item alignment to the levels explained the vast majority of the item difficulties, while other item characteristics were only partially significant predictors for item difficulties. 
Table 4. Correlations between Turkish test and German test scores (RQ3)

\begin{tabular}{|c|c|c|c|c|c|c|}
\hline & \multicolumn{6}{|c|}{ Turkish PV test score } \\
\hline & \multicolumn{2}{|c|}{ Grade 2 ( $N=114)$} & \multicolumn{2}{|c|}{ Grade $3(\mathrm{~N}=170)$} & \multicolumn{2}{|c|}{ Grade $4(\mathrm{~N}=153)$} \\
\hline & $\mathbf{r}$ & $p$ & $\mathbf{r}$ & $p$ & $\mathbf{r}$ & $p$ \\
\hline German PV test score & .747 & $<.001$ & .464 & $<.001$ & .688 & $<.001$ \\
\hline
\end{tabular}

${ }^{\star}$ Note. PV=place value

The third research question concerned, to what extent place value understanding as measured by the translated item collection based on the German model by Herzog et al. (2019) can be identified with place value understanding measured by other Turkish place value tests (RQ3). To investigate the equivalence of the measures, correlations between children's performance in the item collection and a Turkish place value test (Mutlu \& Sarı, 2019) were estimated. As seen in Table 4, there is a positive and significant correlation between all the students' German and Turkish place value test scores in all Grades. While this correlation coefficient is high in the second grade, it is at the middle level in the third and fourth grade.

\section{DISCUSSION}

The results of the Rasch analysis underpin the validity of the model hierarchy in general. Items mostly clustered according to their theoretical allocation in the level sequence. Item difficulties followed the a-priori assumptions based on the model by Herzog et al. (2019), with the exception of five outliers. A comparison of the Turkish results with the German validation study reveals similarities regarding these outliers (Herzog \& Fritz, 2019). In the original German version of the test, items $4 \mathrm{~b}$ and $4 \mathrm{c}$ also deviated into Level III. In addition, items 9c (Level III) and 10c (Level IV) were the easiest items of their level and directly at the border to the next lower level. Thus, the deviations of these items found in the Turkish translation of the test are in line with prior findings. This similarity underpins the assumptions that the deviations do not invalidate the model hierarchy in total. More likely, these items require revisiting, in particular regarding the assessment of individual conceptual development, which was not main aim of this study.

The model validity is also bolstered by the regression models (RQ2). Most variance was explained by the a-priori alignment of the items to the levels. The fit of the first regression model (only level alignment) is within the range of similar approaches (Herzog \& Fritz, 2019; Schulz et al., 2020). Besides the level alignment, illustrations and part-whole aspects were significant predictors, which might correlate with their alignment to the levels, too. Of the ten items with visualizations, 2 were at Level I, 6 at Level II, and 2 at Level III. In contrast, of the nine items with part-whole formats ("fill-in"), 3 were at Level I, Level III, and Level IV each. The alignment to the levels of the items applying to these variables shows visualizations mostly applied to items at lower levels and part-whole formats mostly to items at higher levels. This correlates with the direction of the influence of these variables. As a conclusion, the influence of general item characteristics might stem from the alignment of the characteristic to the levels. In summary, the items difficulty is mostly based on the alignment to one of the conceptual levels of the Herzog et al. (2019) model.

The high correlations between the translated test and an original Turkish test (RQ3) bolster the claim that the model describes place value concepts in Turkish primary school students. The correlation provides convergent validity for the translated German test. These results show that the differences in number word structure in German and Turkish do not affect the development of place value concepts substantially. The unique benefit of the translated test is that the underlying model facilitates formative inferences in terms of concrete teaching methods from the results: If a teacher knows at which level within the sequence a student is, she or he can employ targeted intervention that meets the needs of the particular student (Clements \& Sarama, 2004; Heritage, 2008; Sztajn et al., 2012).

The findings of this study provide first empirical evidence for the usability of the Herzog et al. (2019) model in Turkey. However, the results also show the heterogeneity in the development of place value understanding in Turkish primary school students. In particular, non-canonic representations challenged the students in this study. A possible reason could be that non-canonical representations are rather unusual to Turkish students. That canonical decompositions are relatively easy underpins this assumption: Not decimal decompositions in general, but those that require a conceptual understanding of the base-ten property are challenging. These findings are in line with results from other countries (Herzog et al., 2019; Houdement \& Tempier, 2019; Ross, 1989).

\section{Limitations}

While the hierarchy of the model is bolstered by this cross-sectional study, the developmental claim of the model can only be confirmed in a longitudinal study (Reiss \& Obersteiner, 2019). A longitudinal study can investigate whether children really develop according to the model and rise through the levels over time. Therefore, the model validated in this study may serve as competence framework for place value instruction, but not yet as a developmental progression to design targeted interventions (Clements \& Sarama, 2004).

The presented validation of the level sequence draws on quantitative methods exclusively and especially on item-responsetheory (IRT). While this method is often used to evaluate models of children's developmental trajectories (Balt et al., 2020; Clements et al., 2008; Fritz et al., 2018; Schulz et al., 2020), some researchers also raise criticism (Battista, 2011). As children can only respond to the given stimuli in the chosen paradigm, the test can only assess the extent to which the a-priori described levels are reached. However, it is not possible to assess children's representations of units, tens, and so on directly, as it would be possible in qualitative studies. Rejecting any form of antagonism of qualitative and quantitative methods, this study provides first 
evidence for the validity of the Herzog et al. (2019) model in Turkey. The authors are aware that a qualitative study would further bolster the model validity.

In this study, no control variables were assessed that might affect children's development of place value understanding. Possible variables of interest could be arithmetic performance (beyond place value), transcoding skills, spatial number representations, intelligence, and working memory. While the presented study suggests typical pathways in the development of place value understanding, the processes that lead to a change in children's place value understanding remain unclear. One could think of experience in arithmetic, spatial number representations, or transcoding as motors that drive the development of place value understanding. For example, general early numerical prerequisites such as counting skills (Paydar et al., 2019) might be relevant for the development of a place value understanding. Chan et al. (2014) have shown the importance of base-ten based counting routines for a place value understanding. Moura et al., (2013) have shown that transcoding skills develop during primary school. This development could also involve the development of place value understanding to some extent. In other studies, computation skills in children with low arithmetic performance differed from typically performing children especially when place value information had to be processed (Lambert \& Moeller, 2019). Dietrich et al. (2016) suggested that place value understanding is the underlying knowledge that constitutes the predictive role of number line estimation regarding arithmetic. In a recent study, Sarı and Olkun (2021) have shown that approximate number acuity and place value understanding contribute to the general math achievement as well as to each other. These results might show that teaching place value concepts and relative magnitude of larger numbers contribute to the general math achievement during primary years. However, counter directed or mutual causal relationships are possible, too. Thus, these variables are of great interest in this research. Besides specific numerical skills, working memory and intelligence can have an influence on the development of place value understanding.

\section{Applications}

The level sequence of place value understanding, for which this study provides first empirical evidence in Turkey have two main fields of application. First, the level sequence can be used for the design of formative assessment and targeted intervention. Formative assessment is the identification of children's current knowledge and skills with the intention to design targeted intervention. As the individual development of children can be allocated within the level sequence, intervention informed by such formative assessment can help children with exactly that aspect of place value understanding that they are developing at the moment (Gotwals, 2018; Heritage, 2008). From this perspective, the design of formative assessment and targeted intervention are two sides of the same medal. The level sequence, understood as a developmental progression can form the link between the identification of learning needs and the design of instructive tasks (Clements \& Sarama, 2004).

Second, the model of place value understanding can be used as theoretical framework for further research. Given the desiderates regarding the relation of place value understanding and arithmetic, transcoding, and number line estimation, children at different levels might differ in their performance in these skills. As the levels not only describe a degree of proficiency, but also a conceptual understanding of the place value system, the differences can be linked to children's place value concepts.

Author contributions: All authors have sufficiently contributed to the study, and agreed with the results and conclusions.

Funding: No funding for this research was obtained.

Declaration of interest: There are no political or financial conflicts of interest ties to this research.

Ethical approval: Ethical approval was granted by the local ethics committee.

Informed consent: The children who participated in the research and theirs parents were informed about the study purposes and methods. Participation was voluntary and parents asked for consent beforehand.

\section{REFERENCES}

Balt, M., Fritz, A., \& Ehlert, A. (2020). Insights into first grade students' development of conceptual numerical understanding as drawn from progression-based assessments. Frontiers in Education, 5, 80. https://doi.org/10.3389/feduc.2020.00080

Battista, M. T. (2011). Conceptualizations and issues related to learning progressions, learning trajectories, and levels of sophistication. The Mathematics Enthusiast, 8(3), 507-570. https://scholarworks.umt.edu/tme/vol8/iss3/5

Boulton-Lewis, G. M. (1998). Children's strategy use and interpretations of mathematical representations. The Journal of Mathematical Behavior, 17(2), 219-237. https://doi.org/10.1016/S0364-0213(99)80060-3

Byrge, L., Smith, L. B., \& Mix, K. S. (2014). Beginnings of place value: How preschoolers write three-digit numbers. Child Development, 85(2), 437-443. https://doi.org/10.1111/cdev.12162

Chan, W. W. L., Au, T. K., \& Tang, J. (2014). Strategic counting: A novel assessment of place-value understanding. Learning and Instruction, 29, 78-94. https://doi.org/10.1016/j.learninstruc.2013.09.001

Clarke, B., Cheeseman, J., \& Clarke, D. (2006). The mathematical knowledge and understanding young children bring to school. Mathematics Education Research Journal, 18(1), 78-102. https://doi.org/10.1007/BF03217430

Clements, D. H., \& Sarama, J. (2004). Learning trajectories in mathematics education. Mathematical Thinking and Learning, 6(2), 81-89. https://doi.org/10.1207/s15327833mtl0602_1

Clements, D. H., \& Sarama, J. H. (2014). Learning trajectories: Foundations for effective, research-based education. In A. P. Maloney, J. Confrey, \& K. H. Nguyen (Eds.), Learning over time (pp. 1-30). Information Age. 
Clements, D. H., Sarama, J. H., \& Liu, X. H. (2008). Development of a measure of early mathematics achievement using the Rasch model: the Research-Based Early Maths Assessment. Educational Psychology, 28(4), 457-482. https://doi.org/10.1080/01443410701777272

Cobb, P., \& Wheatley, G. (1988). Children's initial understandings of ten. Focus on Learning Problems in Mathematics, 10 (3), 1-28.

Confrey, J. (2006). The evolution of design studies as methodology. In K. R. Sawyer (Eds.), The Cambridge handbook of the learning sciences (pp. 135-152). Cambridge University Press. https://doi.org/10.1017/CBO9780511816833.010

Dehaene, S. (2011). The number sense: How the mind creates mathematics. Oxford University Press.

Dietrich, J. F., Huber, S., Dackermann, T., Moeller, K., \& Fischer, U. (2016). Place-value understanding in number line estimation predicts future arithmetic performance. British Journal of Developmental Psychology, 34(4), 502-517. https://doi.org/10.1111/bjdp.12146

Dowker, A., \& Roberts, M. (2015). Does the transparency of the counting system affect children's numerical abilities? Frontiers in Psychology, 6, 945. https://doi.org/10.3389/fpsyg.2015.00945

Downton, A., Russo, J., \& Hopkins, S. (2020). Students' understanding of the associative property and its applications: Noticing, doubling and halving, and place value. Mathematics Education Research Journal. https://doi.org/10.1007/s13394-020-00351-w

Fritz, A., Ehlert, A., \& Leutner, D. (2018). Arithmetische Konzepte aus kognitiv-entwicklungspsychologischer Sicht [Arithmetic concepts from a cognitive-developmental psychological point of view]. Journal für Mathematik-Didaktik, 39(1), 7-41. https://doi.org/10.1007/s13138-018-0131-6

Fuson, K. C., Wearne, D., Hiebert, J. C., Murray, H. G., Human, P. G., Olivier, A. I., Carpenter, T. P., \& Fennema, E. (1997). Children's Conceptual Structures for Multidigit Numbers and Methods of Multidigit Addition and Subtraction. Journal for Research in Mathematics Education, 28(2), 130-162. https://doi.org/10.2307/749759

Gebhardt, M., Zehner, F., \& Hessels M. G. P. (2014). Basic arithmetical skills of students with learning disabilities in the secondary special schools. An exploratory study covering fifth to ninth grade. Frontline Learning Research, 3, 50-63. https://doi.org/10.14786/flr.v2i1.73

Gervasoni, A., \& Sullivan, P. (2007). Assessing and teaching children who have difficulty learning arithmetic. Educational \& Child Psychology, 24(2), 40-53.

Gotwals, A. W. (2018). Where are we now? Learning progressions and formative assessment. Applied Measurement in Education, 31(2), 157-164. https://doi.org/10.1080/08957347.2017.1408626

Gravemeijer, K. (2004). Local instruction theories as means of support for teachers in reform mathematics education. Mathematical Thinking and Learning, 6(2), 105-128. https://doi.org/10.1207/s15327833mtl0602_3

Hart, K. (2009). Why do we expect so much? In J. Novotná, \& H. Moraova (Eds.), SEMT 2009. International Symposium Elementary Maths Teaching. August 23 - 28, 2009. Proceedings: The Development of Mathematical Understanding (pp. 24-31). Charles University.

Heritage, M. (2008). Learning progressions: Supporting instruction and formative assessment. http://www.ccsso.org/documents/2008/learning_progressions_supporting_2008.pdf

Herzog, M. \& Fritz, A. (2019). Validation of a Developmental Model of Place Value Concepts. In Graven, M., Venkat, H., Essien, A. \& Vale, P. (Eds). (2019). Proceedings of the 43rd Conference of the International Group for the Psychology of Mathematics Education (Vol. 2, pp.352-359). Pretoria, South Africa: PME

Herzog, M., Ehlert, A., \& Fritz, A. (2017). A competency model of place value understanding in South African primary school pupils. African Journal of Research in Mathematics, Science and Technology Education, 21(1), 37-48. https://doi.org/10.1080/18117295.2017.1279453

Herzog, M., Ehlert, A., \& Fritz, A. (2019). Development of a Sustainable Place Value Understanding. In A. Fritz, V. G. Haase, \& P. Räsänen (Eds.), International handbook of mathematical learning difficulties (pp. 561-579). Springer International Publishing. https://doi.org/10.1007/978-3-319-97148-3_33

Hiebert, J., \& Lefevre, P. (1986). Conceptual and procedural knowledge in mathematics: An introductory analysis. In J. Hiebert (Ed.), Conceptual and procedural knowledge: The case of mathematics (pp. 1-27). Lawrence Erlbaum Associates, Inc.

Houdement, C., \& Tempier, F. (2019). Understanding place value with numeration units. ZDM, 51(1), 25-37. https://doi.org/10.1007/s11858-018-0985-6

Imbo, I., Vanden Bulcke, C., De Brauwer, J., \& Fias, W. (2014). Sixty-four or four-and-sixty? The influence of language and working memory on children's number transcoding. Frontiers in Psychology, 5, 313. https://doi.org/10.3389/fpsyg.2014.00313

Klein, E., Bahnmueller, J., Mann, A., Pixner, S., Kaufmann, L., Nuerk, H.-C., \& Moeller, K. (2013). Language influences on numerical development-Inversion effects on multi-digit number processing. Frontiers in Psychology, $4,480$. https://doi.org/10.3389/fpsyg.2013.00480

Ladel, S., \& Kortenkamp, U. (2016). Development of a flexible understanding of place value. In T. Meaney, O. Helenius, M.-L. Johansson, T. Lange, \& A. Wernberg (Eds.), Mathematics education in the early years - Results from the POEM2 Conference (pp. 289-307). Springer. https://doi.org/10.1007/978-3-319-23935-4_16

Lambert, K., \& Moeller, K. (2019). Place-value computation in children with mathematics difficulties. Journal of Experimental Child Psychology, 178, 214-225. https://doi.org/10.1016/j.jecp.2018.09.008 
Laski, E. V., Ermakova, A., \& Vasilyeva, M. (2014). Early use of decomposition for addition and its relation to base-10 knowledge. Journal of Applied Developmental Psychology, 35(5), 444-454. https://doi.org/10.1016/j.appdev.2014.07.002

Linacre, J. M. (2002). What do infit and outfit, mean-square and standardized mean? Rasch Measurement Transactions, $16(2), 878$.

Lonnemann, J., \& Yan, S. (2015). Does number word inversion affect arithmetic processes in adults? Trends in Neuroscience and Education, 4(1-2), 1-5. https://doi.org/10.1016/j.tine.2015.01.002

MacDonald, A. (2008). But what about the Oneths? A year 7 Student's misconception about decimal place value. Australian Mathematics Teacher, 64(4), 12-15.

McGuire, P., \& Kinzie, M. B. (2013). Analysis of place value instruction and development in pre- kindergarten mathematics. Early Childhood Education Journal, 41(5), 355-364. https://doi.org/10.1007/s10643-013-0580-y

Ministry of Education (2018). Matematik dersi öğretim programı (ilkokul ve ortaokul 1, 2, 3, 4, 5, 6, 7 ve 8. sınıflar) öğretim programı [Mathematics lesson curriculum (primary and secondary school 1, 2, 3, 4, 5, 6, 7 and 8th grades) curriculum].

Moloney, K., \& Stacey, K. (1997). Changes with age in students' conceptions of decimal notation. Mathematics Education Research Journal, 9(1), 25-38. https://doi.org/10.1007/BF03217300

Moura, R., Wood, G., Pinheiro-Chagas, P., Lonnemann, J., Krinzinger, H., Willmes, K., \& Haase, V. G. (2013). Transcoding abilities in typical and atypical mathematics achievers: The role of working memory and procedural and lexical competencies. Journal of Experimental Child Psychology, 116(3), 707-727. https://doi.org/10.1016/j.jecp.2013.07.008

Mutlu, Y., \& Sarı, M.H. (2019). ilkokul öğrencilerinin basamak değeri kavrayışlarının geliştirilmesi [Developing primary school students' understanding of place value]. Kastamonu Education Journal, 27(2), 657-667. https://doi.org/10.24106/kefdergi.2645

Nataraj, M. S., \& Thomas, M. O. (2007). Developing the concept of place value. In J. Watson, \& K. Beswick (Eds.), Proceedings of the 30th Annual Conference of the Mathematics Education Research Group of Australasia (Vol. 2, pp. 523-532). MERGA Inc.

OECD (2019), PISA 2018 results (Volume II): Where all students can succeed, PISA, OECD Publishing, Paris. https://doi.org/10.1787/b5fd1b8f-en

Olkun, S., Reçber, H., Ata, A., Özer, E., \& Çelebi, Ö. (2011). Türk çocuklarının bilişsel sayı temsilinin Çinli, Fransız, Japon, Koreli, İsveçli ve Amerikalı yaşıtlarıyla karşılaştırılması [Comparison of Turkish children's cognitive number representation with their Chinese, French, Japanese, Korean, Swedish and American peers]. Ankara Üniversitesi Eğitim Bilimleri Fakültesi Dergisi, 44(1), 79-90. https://doi.org/10.1501/Egifak_0000001216

Paydar, S., \& Sarı, M. H. (2019). İlkokul ikinci ve üçüncü sınıf öğrencilerinin basamak değeri kavrayışları [Place value perceptions of primary school second and third grade students]. In S. Olkun (Ed.), ilköğretim çalışmaları bütünsel açıdan çocuk (pp. 97-116). Pegem Academy Publishing. https://doi.org/10.14527/9786058011410.06

Paydar, S., Doğan, A., \& Şahin, A. E. (2019). An analysis of primary first grade students' readiness in natural numbers. Elementary Education Online, 18(3), 1059-1072. https://doi.org/10.17051/ilkonline.2019.610645

Primary School Mathematics Curriculum (2018). Matematik dersi öğretim programı (ilkokul ve ortaokul 1, 2, 3, 4, 5, 6, 7 ve 8. sınıflar) ögretim programı [Mathematics lesson curriculum (primary and secondary school 1, 2, 3, 4, 5, 6, 7 and 8th grades) curriculum]. Ankara: MEB Press.

Reiss, K., \& Obersteiner, A. (2019). Competence models as a basis for defining, understanding, and diagnosing students' mathematical competences. In A. Fritz, V. G. Haase, \& P. Räsänen (Eds.), International Handbook of Mathematical Learning Difficulties (pp. 43-56). Springer International Publishing. https://doi.org/10.1007/978-3-319-97148-3_4

Rittle-Johnson, B., \& Schneider, M. (2015). Developing conceptual and procedural knowledge of mathematics. In R. C. Kadosh, \& A. Dowker (Eds.), Oxford handbook of numerical cognition (pp. 1118-1134). Oxford University Press. https://doi.org/10.1093/oxfordhb/9780199642342.013.014

Ross, S. H. (1989). Parts, wholes, and place value: A developmental view. The Arithmetic Teacher, 36(6,), 47-51. https://doi.org/10.5951/AT.36.6.0047

Sarı, M. H., \& Olkun, S. (2019). Relationship between place value understanding, arithmetic performance and mathematics achievement in general. ilköğretim Online, 18(2), 953-958. https://doi.org/10.17051/ilkonline.2019.562086

Sarı, M. H., \& Olkun, S. (2021). The relationships among number line estimations, mathematics achievement and place value understanding. Journal of Education and Future, 19, 37-47. https://doi.org/10.30786/jef.729843

Schulz, A., Leuders, T., \& Rangel, U. (2020). The use of a diagnostic competence model about children's operation sense for criterion-referenced individual feedback in a large-scale formative assessment. Journal of Psychoeducational Assessment, 38(4), 426-444. https://doi.org/10.1177/0734282918823590

Siegler, R. S., \& Alibali, M. W. (2005). Children's thinking (4th ed). Pearson Education/Prentice Hall.

Sztajn, P., Confrey, J., Wilson, P. H., \& Edgington, C. (2012). Learning trajectory based instruction: Toward a theory of teaching. Educational Researcher, 41(5), 147-156. https://doi.org/10.3102/0013189X12442801

Van de Walle, J., Karp, K., \& Bay-Williams, J. (2016). Elementary and middle school mathematics: Teaching developmentally (9th ed.). Pearson Education.

Wilson, M. (2005). Constructing measures: An item response modelling approach. Lawrence Erlbaum Associates. 
Wright, R. J., Ellemor-Collins, D., \& Lewis, G. (2007). Developing pedagogical tools for intervention: Approach, methodology, and an experimental framework. In J. Watson \& K. Beswick (Eds.), Mathematics: Essential research, essential practice (Proceedings of the 30th annual conference of the Mathematics Education Research Group of Australasia, Hobart, Vol. 2, pp. 843-852). MERGA.

Zuber, J., Pixner, S., Moeller, K., \& Nuerk, H.-C. (2009). On the language specificity of basic number processing: Transcoding in a language with inversion and its relation to working memory capacity. Journal of Experimental Child Psychology, 102(1), 60-77. https://doi.org/10.1016/j.jecp.2008.04.003

Zwick, R., Thayer, D. T., \& Lewis, C. (1999). An empirical Bayes approach to Mantel-Haenszel DIF analysis. Journal of Educational Measurement, 36(1), 1-28. https://doi.org/10.1111/j.1745-3984.1999.tb00543.x 